CIUDAD Y TERRITORIO

ESTUDIOS TERRITORIALES

ISSN(P): 1133-4762; ISSN(E): 2659-3254

Vol. LIII, № 207, primavera 2021

Págs. 77-94

https://doi.org/10.37230/CyTET.2021.207.05

CC BY-NC-ND

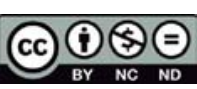

\title{
¿Es recuperable la ciudad como espacio para la infancia? Aproximación teórica desde la perspectiva del urbanismo social, participativo y sostenible
}

\author{
Juan SeVILLA ${ }^{(1)}$ \\ Diego CoRrochano ${ }^{(2)}$ \\ Alejandro GómEZ-GONÇALVES ${ }^{(3)}$ \\ Héctor Rato ${ }^{(4)}$
}

\author{
(1) Departamento de Geografía. Universidad de Oviedo. \\ (2)Departamento de Didáctica de las Matemáticas y de las Ciencias Experimentales. \\ Universidad de Salamanca \\ ${ }^{3}$ Departamento de Geografía. Universidad de Salamanca. \\ ${ }^{(4)}$ Colegio Internacional Meres
}

RESUMEN: La concepción que el ser humano tiene del espacio urbano es decisiva en la estructuración de su pensamiento. Este hecho tiene una gran importancia para la población infantil al condicionar el desarrollo de experiencias que asientan destrezas y capacidades, favoreciendo el aprendizaje significativo. Sin embargo, la progresiva deshumanización de las ciudades ha ido restringiendo el contacto directo de la población infantil con el medio urbano. En este trabajo se analizan algunas iniciativas de reencuentro de este sector de la población con la ciudad (La Ciudad de los Niños por Francesco Tonucci, Ciudades Amigas de la Infancia de UNICEF) y el papel que hoy en día está jugando el urbanismo social, participativo y sostenible como corriente convergente con dichas iniciativas. A través una revisión de documentación institucional, de proyectos y de fuentes bibliográficas se analizan los fundamentos de estas formas de entender la construcción de la ciudad. Y se estudian algunos ejemplos de nuestro país que evidencian cómo esta corriente urbanística puede servir como modelo de intervención en municipios comprometidos con los programas defensores de la infancia.

PALABRAS CLAVE: Ciudad; Urbanismo; Infancia; Tonucci; UNICEF.

Recibido: 08.03.2020; Revisado: 13.07.2020

Correo electrónico: sevillajuan@uniovi.es; № ORCID: https://orcid.org/0000-0001-6235-0020;

Correo: dcf@usal.es; № ORCID: https://orcid.org/0000-0002-6085-9744;

Correo: algomez@usal_es; № ORCID: https://orcid.org/0000-0002-4988-4623:

Correo: hector.rato@gmail.com; № ORCID: https://orcid.org/0000-0002-4492-0736 "

Los autores agradecen los comentarios y sugerencias realizados por los evaluadores anónimos, que han contribuido a mejorar y enriquecer el manuscrito original [1] Los autores desean agradecer el interés y el permiso de reproducción de imágenes de Francesco Tonucci y de los equipos de Col.lectiu Punt 6, HUCAMP Arquitectos y Paisaje Transversal. Ha sido fundamental el asesoramiento prestado por İ́caro Obeso durante el período de investigación. 


\section{Is the city recoverable as a space for children? Theoretical approach from the perspective of social, participatory and sustainable urban planning}

ABSTRACT: The conception of urban space is decisive in the structuring of thought. It is important for children because it conditions the development of experiences that consolidate skills and abilities, favouring meaningful learning. However, the development of children has encountered obstacles in the contemporary period due to a progressive dehumanization of cities. In this study we have analyzed some initiatives that encourage children encounter with their cities (The City of Children by Francesco Tonucci; Child Friendly Cities by UNICEF), and also the role that social, participatory and sustainable urban planning is playing as converging current with these initiatives. The fundamental bases of these ways of understanding the city are analyzed through a review of institutional documents, projects and bibliographic sources. And some examples from Spain are studied in order to demonstrate how this urban trend can serve as a model of intervention in municipalities committed to child defence programs.

KEYWORDS: City; Urban planning; Childhood; Tonucci; UNICEF.

\section{Introducción: habitabilidad y potencial educativo de la ciudad}

os factores y las experiencias espaciales son esenciales en la adquisición de autonomía y responsabilidad, así como en la estructuración del pensamiento, en la construcción de la identidad personal y en la formación de una conciencia cívica y cultural durante la infancia. Resultan decisivos en la adaptación social y en el desarrollo intelectual y condicionan, a la postre, el mantenimiento de una sociedad de progreso y civilizada (ARANDA, 2001, 2010; HeRnÁndeZ, 1986; Ministerio de EduCACIÓn, Cultura y Deporte, 2014; Ministerio de EduCACIÓN y Ciencia, 2006, 2007).

La concepción y el diseño del espacio urbano, en el que se concentra la mayor parte de la población de los países europeos (EUROSTAT, 2016), se convierte en un asunto esencial para los procesos de enseñanza-aprendizaje en el período contemporáneo. Por ello, han adquirido gran importancia desde la perspectiva educadora. Una mayor facilidad para desenvolverse de manera segura y autónoma en los primeros años de vida, desarrollando destrezas y capacidades individuales, multiplicando y diversificando las experiencias de exploración, observación y reflexión, favorece el aprendizaje significativo, a la vez que propicia una educación más sólida (RıssotTo \& TonUCCI, 2002).

La organización de la ciudad, según sea el diseño y los criterios con que se concibe, puede enriquecer o, por el contrario, dificultar la exploración directa del entorno. Puede condicionar las capacidades para identificar, interpretar, diferenciar, relacionar y clasificar las propiedades y los efectos de aquellos elementos y dimensiones que configuran los procesos naturales y humanos, las formas de vida, las manifestaciones culturales, etc. Estimula o limita, por tanto, la conceptualización del espacio y de la sociedad. El medio urbano constituye así, al tiempo, escenario y objeto de aprendizaje (Aranda, 2010; Ministerio de Educación, Cultura y Deporte, 2014; Ministerio de Educación y Ciencia, 2006, 2007).

El diseño de espacios para el desarrollo en sociedad constituye asimismo una responsabilidad pública en la medida en que su habitabilidad y las experiencias vitales derivadas, incluidas las relaciones interpersonales, pueden intervenir en la formación del pensamiento cívico. Su configuración puede alentar la transmisión de un sistema de valores reconocidos que convierten al individuo en ciudadano: le conciencian desde el punto de vista de la cohesión y la interdependencia positiva, de la mejora y la transformación social, y le animan a la participación en esferas como la solidaridad, la igualdad, la no discriminación y la resolución pacífica de conflictos, así como en el cuidado del legado cultural y en la relación de respeto del ser humano con el medio (ARANDA, 2001; CAlle \& al., 2008; HeRnÁNDEZ, 1986; MINISTERIO de Educación, Cultura y Deporte, 2014; MinisTERIO de EdUCACIÓN Y CIENCIA, 2006; 2007; SeVILla, 2014; TEY \& CIFRE-MAS, 2011).

Aparte del aprendizaje informal que resulta de las vivencias cotidianas al margen de la escolarización, la morfología, la estructura y la función del 
espacio urbano pueden aprovecharse igualmente en la programación didáctica de la enseñanza reglada como recurso externo que fomenta la creatividad y la curiosidad, elevando la motivación, la atención y la participación activa. La ciudad se convierte en un entorno ideal para sustentar la enseñanza dirigida al conocimiento del medio social, pero también ofrece múltiples posibilidades para aprender sobre el medio natural (CAÑAL \& García-CARMONA \& CRUZ-GuZMÁn, 2016). Además, el entorno urbano es especialmente útil cuando se trabajan contenidos naturales, sociales y culturales de manera dinámica e interrelacionada (GómeZ-GonçAlVES \& CoRRochANo, 2018). Su aprovechamiento es pertinente dadoque se adecúa a las características contextuales y cognitivas de los alumnos, respetando principios metodológicos fundamentales en las primeras etapas educativas: la globalidad, la significatividad, la interacción, la experimentación, el trabajo cooperativo y el carácter lúdico, entre otros. Asimismo, mantiene la premisa de la búsqueda del aprendizaje a través de la progresiva construcción de esquemas de conocimiento interconectados y asentados en la comprensión de las relaciones entre contenidos secuenciados. Por tanto, se puede identificar una clara vocación pedagógica de los espacios urbanos que cristaliza en el concepto de "ciudad educadora", compuesto por tres ámbitos o dimensiones en los que la ciudad contribuye a formar al individuo: a) la ciudad como contenedor de recursos didácticos; b) la ciudad como agente educativo del que aprender; c) la ciudad como contenido educativo (TRILLA, 2005).

La programación de actividades en un espacio de aprendizaje externo al aula aporta, en definitiva, un elevado valor añadido a la acción educativa con la aplicación de métodos consecuentes con los principios señalados, como el aprendizaje basado en la resolución de problemas o el método científico, entre otros (ARANDA, 2010; Cuenca, 2011; Ministerio de Educación, Cultura y Deporte, 2014; Ministerio de Educación y Ciencia, 2006, 2007).

En cualquier caso, el desarrollo de experiencias con cierto grado de autonomía en contacto directo con el entorno urbano (por ejemplo, la exploración y recogida de información, la orientación, la manipulación, la identificación e interpretación de atributos y cualidades de las realidades observadas, la formulación y verificación de hipótesis, etc.), encuentra obstáculos en el período contemporáneo debido a la progresiva deshumanización y merma ambiental de las ciudades, que han priorizado la función económica al bienestar ciudadano. Los espacios apropiados para interactuar, donde las situaciones y los fenómenos reales que suscitan curiosidad, interés, asombro o sorpresa se convierten en motivo de aprendizaje y enriquecimiento intelectual, pierden protagonismo en tiempo reciente o presentan características contrarias a las necesidades de los grupos con mayor dependencia, entre ellos la población infantil (CUENCA, 2011; FREEMAN \& TRANTER, 2011; LoPES \& CoRDOVIL \& NeTO, 2014; TonUCCI, 2009b).

El hecho de que actualmente los niños vivan en ambientes urbanos desnaturalizados y tecnológicos, pero sin disfrutar del aire libre y de espacios verdes, propicia que se pierdan experiencias vitales fundamentales para su aprendizaje. Actualmente los niños juegan mucho menos al aire libre de lo que lo hacían generaciones pasadas (CLEMENTS, 2004; Segovia, 2017). En las ciudades de hoy en día se han incrementado las zonas de ocio infantil asociadas al consumo localizadas en espacios cerrados (centros comerciales). La aparición de las nuevas tecnologías como forma de diversión, que incluso a veces llegan a intentar suplir mediante entornos virtuales la propia naturaleza, junto la urbanización deshumanizada, han contribuido a disminuir de manera considerable el tiempo que los niños pasan en espacios exteriores, ocasionando el incremento de la obesidad infantil y la falta de socialización (FreIRE, 2011; NAVARRo, 2013). En este sentido, son bien conocidos los beneficios físicos, mentales y sociales que proporciona el contacto con el entorno (ver revisiones en GILL, 2014; KENIGER \& al., 2013). En el caso de la infancia en concreto, este contacto con los elementos naturales del medio favorece el desarrollo intelectual, social y físico de los niños (KeLleRT, 2002), aumentando su salud y bienestar (MALLER \& TOWNSEND, 2006), reduciendo sus niveles de ansiedad (WELLS \& EVANS, 2003), favoreciendo la creatividad y la resolución de problemas (MALLER \& TOWNSEND, 2006) y ayudando a mejorar sus relaciones sociales (BURDETTE \& WHITAKER, 2005). Por lo tanto, parece necesario que las ciudades promocionen y proporcionen espacios verdes y con calidad ambiental para que el niño pueda experimentar por sí mismo y de forma autónoma, junto a sus iguales, los beneficios de interactuar con los elementos naturales del medio. Estos espacios verdes deben integrarse en múltiples escalas, desde el paisajismo alrededor de las viviendas y escuelas, hasta los sistemas conectados de corredores urbanos, vías verdes, parques y jardines (CHAWLA, 2015).

A mediados de la pasada centuria se conocen en Europa propuestas singulares que plantean la dotación de espacios específicos para actividades lúdicas en la ciudad: por ejemplo, la de la paisajista Lady Allen of Hurtwood en barrios londinenses, defendiendo la creación de áreas de juego como 
soporte para ejercitar la libertad individual; o la de la urbanista Jakoba Mulder en Amsterdam, encaminada al aprovechamiento de intersticios en la trama urbana para satisfacer las necesidades de la población infantil (GARCíA-GonZÁLEZ \& GUERRERO, 2019). Esta preocupación se mantiene en las décadas siguientes, en la medida en que las dinámicas de los espacios urbanos no resuelven suficientemente esta cuestión.

Desde el ámbito académico e institucional se ha tomado conciencia de estos hechos en las últimas tres décadas y se han concebido e impulsado iniciativas que persiguen la recuperación de la ciudad como espacio para el desarrollo intelectual y social de la infancia (BARTLETT \& al., 1999; BOYDEN \& Holden, 1991; Driskell, 2002; Simone \& EsteVes, 2017; SPENCER \& BLADES, 2005). Es particularmente destacable el célebre trabajo La Ciudad de los Niños de Francesco Tonucci, maestro, pedagogo e investigador del Instituto de Psicología del Consiglio Nazionale delle Ricerche (CNR) italiano, en la base del proyecto homónimo iniciado en Italia en 1991 y promovido desde 1997 a escala internacional (Asociación de Viandantes A PIE, 2002; MARTíneZ, 2004; TONUCCI, 1994, 2009a, 2009b). Es también muy conocida la iniciativa liderada por United Nations International Children's Emergency Fund (UNICEF) bajo la denominación Ciudades Amigas de la Infancia, que comparte principios con el proyecto de Tonucci y se gesta en la misma época a partir de dos hechos principales: la puesta en marcha del programa Alcaldes defensores de los niños en 1992 (en Dakar, Senegal), cuando el papel de los Gobiernos locales en el cumplimiento de los derechos de los niños se incorpora a la agenda internacional; y la declaración del bienestar de los niños como indicador de un entorno saludable, democrático y con buena gobernanza tomada durante la conferencia de Naciones Unidas sobre asentamientos humanos Habitat II (Estambul), en 1996 (UNICEF Comité Español, https:// ciudadesamigas.org/municipio-amigo-infancia/).

Desde una perspectiva teórica en el campo de la planificación y la ordenación del espacio urbano, el presente trabajo tiene por objetivo subrayar la validez de nuevas formas de diseño de la ciudad que vienen a favorecer su rehumanización y su recuperación ambiental y tienden a invertir la tendencia denunciada en los proyectos en favor de la infancia. Más específicamente, se analiza el emergente urbanismo social, participativo y sostenible preconizado por un número creciente de colectivos profesionales y ciudadanos, con un corpus teórico y metodológico progresivamente construido durante las últimas décadas, como herramienta válida para facilitar el reencuentro de la población infantil con la ciudad. Este objetivo se apoya en la constatación de que esta corriente urbanística ha registrado algunos resultados satisfactorios en la mejora de la habitabilidad y de la experiencia urbana en operaciones parciales recientes. De ahí la pertinencia de su valoración como modelo a extender en el mundo urbano contemporáneo (y particularmente en las redes de municipios certificados como afines a la infancia). En definitiva, el urbanismo social, participativo y sostenible se plantea aquí como corriente a tener en cuenta por las instancias responsables del planeamiento urbano para beneficio de todos los grupos de población incluida la infantil, que es clave en el desarrollo futuro de la ciudad; aparte de servir como necesario modelo de intervención para los gobiernos locales comprometidos con los programas de Tonucci y UNICEF en el apartado de la planificación física.

\section{Procedimiento de trabajo}

Para responder a la pregunta de si es recuperable la ciudad como espacio para la infancia, desde la perspectiva planteada, se ha seguido un procedimiento de trabajo basado en una profunda revisión de documentación institucional, de proyectos y de fuentes bibliográficas desde dos puntos de vista pocas veces coincidentes: desde una vertiente pedagógico-educativa y desde otra vertiente urbanístico-geográfica. Para ello, se ha comenzado por consultar los documentos oficiales del Estado español que regulan y ordenan las enseñanzas en Educación Infantil y Primaria, particularmente en lo que se refiere a objetivos, contenidos y principios metodológicos, además de bibliografía especializada en el campo de la conceptualización del espacio y la sociedad, en la perspectiva de la didáctica de las ciencias sociales y experimentales, de la pedagogía y de la psicología ambiental.

Por otro lado, se ha realizado una aproximación sintética a la misma cuestión desde la óptica del urbanismo, prestando atención a la evolución de los espacios urbanos en la última centuria, en sus rasgos morfológicos, estructurales y funcionales, con el fin de observar en qué medida han mudado su concepción y su diseño. En este punto, han sido empleados estudios geográficos y arquitectónicos sobre el crecimiento espacial, la reforma y la rehabilitación de las ciudades contemporáneas, y también acerca de la función urbana desde una perspectiva sociológica y de ecología urbana, así como los propios estudios y los célebres dibujos en los que Francesco Tonucci presenta su teoría sobre La Ciudad de los Niños. El trabajo se completa, en esta fase, con imágenes aéreas del Vuelo Americano Serie B 1956-57 y del Plan Nacional 
de Ortofotografía Aérea (PNOA) que evidencian las características urbanas señaladas.

Una vez establecida la base teórica, la investigación se ha centrado en caracterizar los dos principales movimientos internacionales de recuperación del espacio urbano para la población infantil, el señalado de Tonucci y el impulsado por UNICEF para crear Ciudades Amigas de la Infancia, coetáneos y convergentes en sus postulados esenciales. Se han expuesto las claves que sus promotores y los académicos establecen para adecuar la ciudad a las necesidades de los niños, de acuerdo con sus publicaciones y documentos gráficos fundamentales; lo que ha conducido, en suma, junto a las consideraciones pedagógicas introductorias, a la identificación de una serie de rasgos, a modo de estándares de calidad, que permiten caracterizar la afinidad de una ciudad a las necesidades de la infancia.

A continuación, dado el objetivo de evidenciar el interés del urbanismo social, participativo y sostenible como herramienta en la recualificación de la ciudad como espacio para el desarrollo integral de la infancia (necesaria en el cometido de alcanzar las condiciones óptimas señaladas por Tonucci y UNICEF), se ha llevado a cabo una profundización de la revisión bibliográfica y de la consulta documental institucional. En concreto, se han seleccionado trabajos que exponen los fundamentos teóricos y metodológicos de esta corriente urbanística. Se trata de publicaciones y documentos técnicos de investigadores y colectivos profesionales responsables de su impulso.

Finalmente, para valorar si la corriente urbanística aludida lleva a la práctica los estándares de afinidad con la infancia previamente definidos, se ha revisado una muestra de proyectos representativos, tanto con enfoque transversal como sectoriales temáticos, realizados por equipos que, además, han contribuido al enriquecimiento teórico y metodológico de este movimiento en España. Se han analizado sus planteamientos y resultados, y se han reproducido algunos planos, infografías y fotografías que ilustran sus características principales. También se han elaborado algunas figuras a partir de los originales (confeccionados, en este caso, con Adobe lllustrator). Se opta por un contraste con ejemplos españoles por la exposiciónde nuestras ciudades a tendencias y ritmos económicos muy contrapuestos en las últimas décadas, por su contenido sociodemográfico cambiante en este inicio de siglo y por permanecer pendiente, más que en países de su entorno, el reencuentro entre naturaleza y ciudad. Motivos, todos ellos, querealzan el impacto que han podido tener las nuevas visiones de la ordenación de la ciudad.

\section{3. ¿Qué implica la adecuación del espacio urbano a las necesidades de la infancia?}

\author{
3.1. La Ciudad de los Niños \\ según Francesco Tonucci
}

Al avanzar la pasada centuria, la ciudad ha tendido a planificarse, regularse y reformarse atendiendo, sobre todo, a los requerimientos de sus funciones económicas principales y del flujo del tráfico motorizado generado por estas (FIG. 1). Se ha generalizado una pérdida de escala humana que coloca al peatón en segundo plano, incluso fuera del nivel de calle, en muchos casos (HERRMANN, 2016; TonucCl, 2009a). Pese a que en nuestro país se ha impuesto la planificación a la hora de diseñar e incorporar las nuevas piezas urbanas, los espacios dotacionales para el encuentro, la relación y la construcción social han ido perdiendo protagonismo o se han constituido de acuerdo con los estándares que marca la legislación de manera inconexa y limitados por una red viaria pensada para la circulación rodada (FIGs. 2a y 2b), dentro de una trama urbana donde progresivamente se ha ido diluyendo la concepción del espacio vivido. Entre los ejemplos más evidentes y quizás más estudiados se encuentran los espacios verdes urbanos, cuya construcción en nuestras principales ciudades se ha realizado de manera estricta desde mediados de la década de los ochenta del siglo pasado, pero cuya integración en el tejido urbano consolidado y en la ciudad vivida por los ciudadanos sigue presentando grandes desafíos (DíAZ \& Rodríguez, 2003; Gómez, 2013; Gómez-GonçALVES \& SÁnchez \& Ceballos, 2018). Por tanto, progresivamente la ciudad se convierte en un lugar más fragmentado y jerarquizado socialmente que, además, por lo señalado, pierde identidad, solidaridad y seguridad. Asimismo, viene a caracterizarse por una creciente especialización (Tonuccl, 1994, 2009a, 2009b). En efecto, se produce una especialización funcional de los distritos urbanos que origina en el ciudadano, cada vez más, la pérdida de una experiencia urbana completa e integrada en un espacio fácilmente abarcable. Se detecta, en definitiva, una merma de la riqueza de experiencias al transitar y vivir la ciudad. De hecho, el ciudadano necesita emplear con frecuencia el transporte rodado para desplazarse con el fin de acceder a determinados servicios, equipamientos e infraestructuras dotados en escaso número o con una localización única (Fernández \& Fernández, 2019; SevilLa, 2014)

Dado este devenir de la ciudad, las consecuencias son importantes para la infancia: puede alterarse 
Estudios

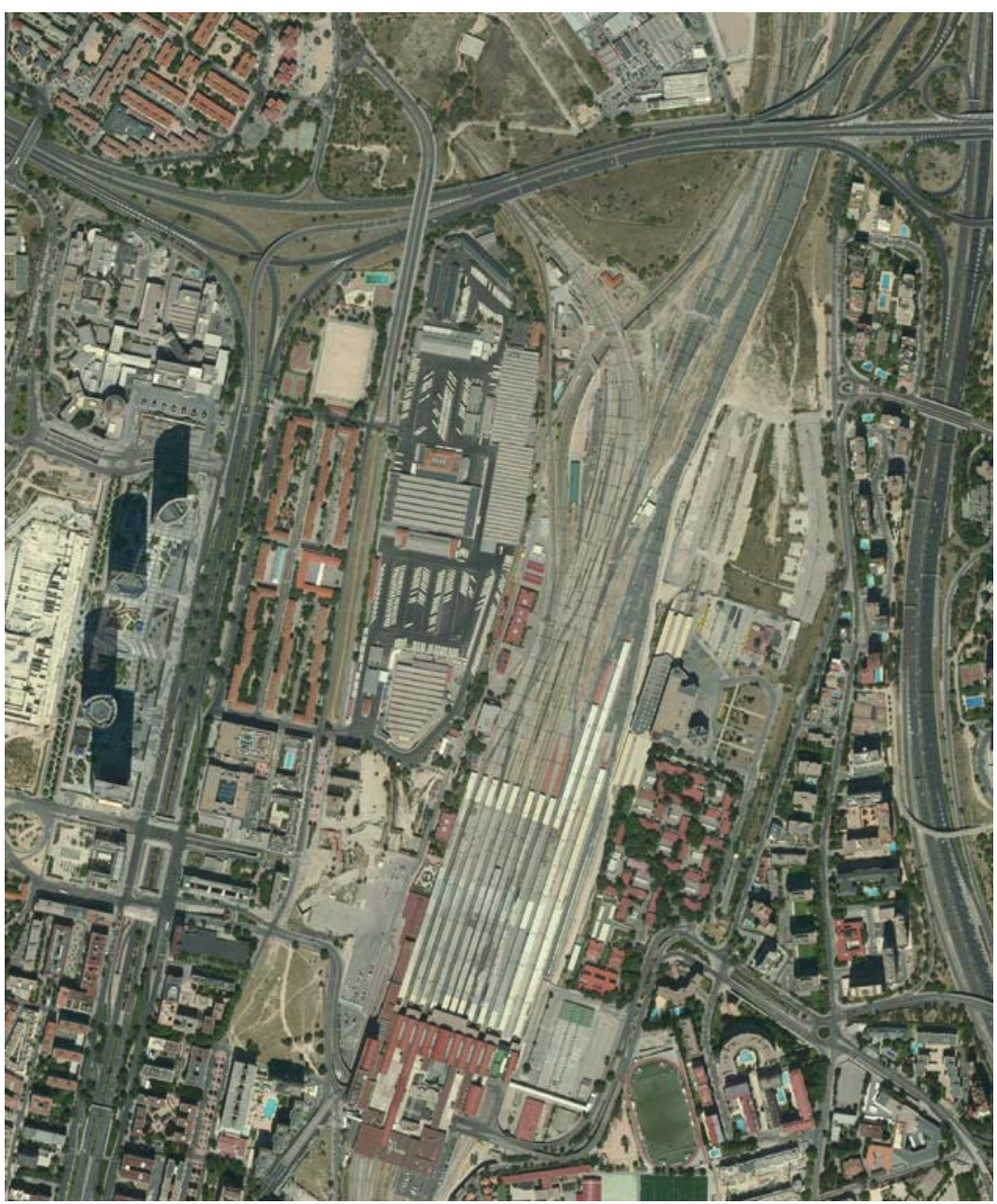

FIG. 1/ Preponderancia de la función económica y pérdida de la escala humana en la concepción de la ciudad. Entorno de la estación de Chamartín en el norte de Madrid: imagen aérea del distrito.

Fuente: Plan Nacional de Ortofotografía Aérea-PNOA, 2017.
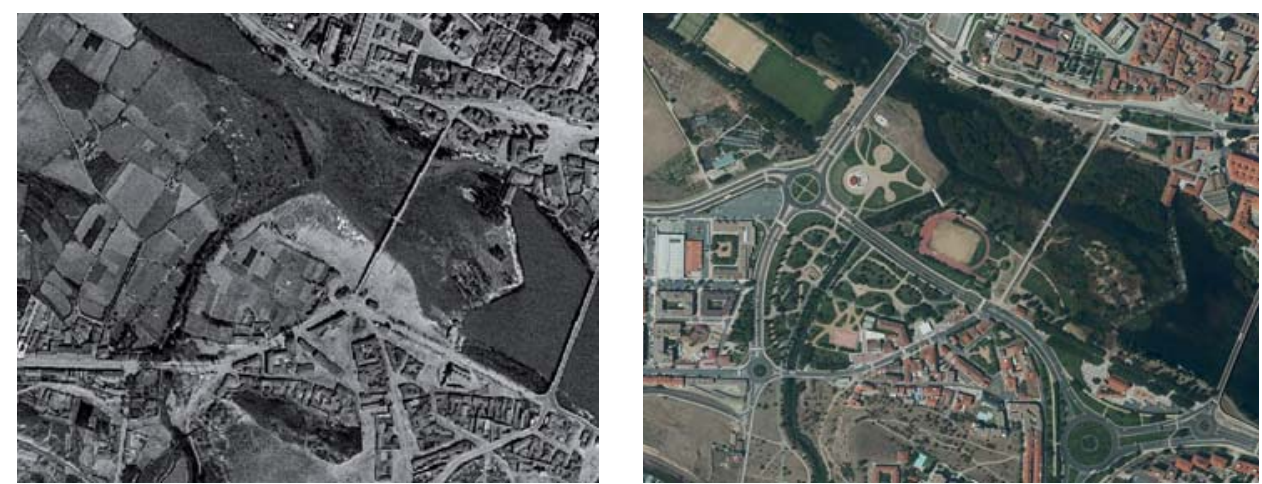

FIGS. 2 A Y 2 B/ Los espacios para el paseo, el ocio y la relación social se convierten en sectores inconexos, limitados por un complejo entramado de red viaria concebida para el transporte motorizado. Ribera meridional del río Tormes en Salamanca, a mediados de la década de 1950 (izquierda) y en 2017 (derecha).

Fuente: Vuelo Americano Serie B 1956-57 y PNOA 2017. 
el movimiento y el disfrute autónomo de experiencias fundamentales para el crecimiento y la puesta a prueba de capacidades fundamentales, como la socialización, el juego, la exploración, el descubrimiento, la superación de obstáculos, la detección del riesgo, la resolución de problemas, etc. (FIG. 3). Al perder capacidad de movimiento autónomo se genera entonces mayor dependencia de otros entornos, recursos y agentes más limitantes para el aprendizaje y el entretenimiento. Incluso, desde el punto de vista de los docentes, el uso de los espacios urbanos y de la enseñanza fuera del aula está disminuyendo debido a la gran cantidad de problemas que supone para los educadores abandonar la escuela y recorrer la ciudad con grupos de niños y niñas (DYMENT, 2005), aunque se hayan demostrado los efectos positivos que tiene el desarrollo de la enseñanza en espacios donde los alumnos entran en contacto con la naturaleza (Almers \& Askerlund \& KJellström, 2018; Malberg DYG \& WISTOFT, 2018).

En ese contexto, promovido por el CNR italiano a partir de 1991 y encabezado por Francesco Tonucci, el proyecto La Ciudad de los Niños alienta a las Administraciones locales a adoptar una nueva forma de gobierno municipal tomando como parámetro al niño y sus necesidades. Se articula sobre dos ejes: la recuperación de la autonomía de movimiento y la participación de los niños en el gobierno de la ciudad a través de consejos específicos (Alaparone \& Rissotto, 2001; TONUCCI, 1994, 2009a, 2009b).

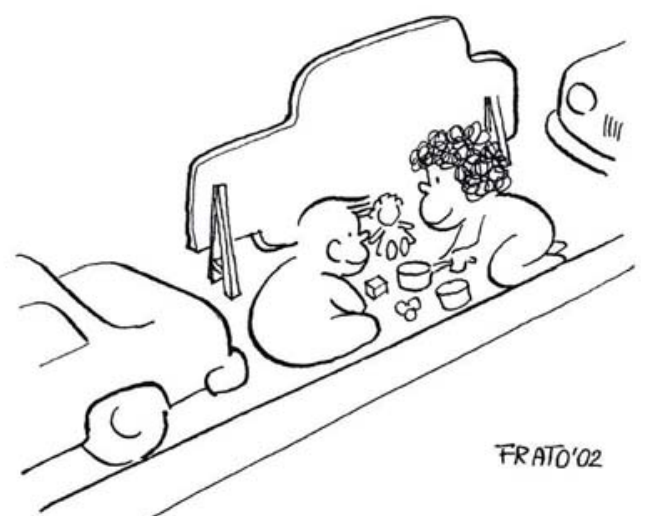

FIG. 3/ El proyecto de Francesco Tonucci ha trascendido asimismo en razón de su ingenio creativo, que reivindica un espacio adecuado para el desarrollo intelectual y social de la infancia. Reproducción de dibujo de 2002.

Fuente: TonucCl, 2009b.

2 El artículo recoge lo siguiente: "1. Los Estados Partes garantizarán al niño que esté en condiciones de formarse un juicio propio el derecho de expresar su opinión libremente en todos los asuntos que afectan al niño, teniéndose debidamente en cuenta las opiniones del niño, en función de la edad y madurez del niño. 2. Con tal fin, se dará en
Para recuperar autonomía de movimiento, el proyecto propone, entre otras medidas, que los niños y las niñas vayan a la escuela sin compañía de un adulto a partir de los 6 años. Es una propuesta de difícil aplicación pero posible si se trabaja y colabora de manera conjunta con las familias, las escuelas y las instituciones locales, estudiando los itinerarios, sus características y las potenciales intervenciones, incluida la colaboración gremial y ciudadana organizada para una vigilancia social de la infancia. Además de fomentar la autonomía, esta práctica inculca en la comunidad valores de solidaridad y educación vial (GILES-CORTI \& al., 2011; LIN \& al., 2017; Tonuccl, 2009a).

Por otro lado, el proyecto busca facilitar la experiencia infantil en la ciudad promoviendo la habilitación de lugares en los que los niños se desenvuelvan para desarrollar y explotar sus capacidades sin la compañía y el control constante del adulto: vías peatonales, aceras, redes de carriles para bici, plazas, parques y espacios públicos amplios con diseños ricos en mobiliario y juegos, variados y no estandarizados. Se trata de una visión del espacio que emana de la interpretación que la propia infancia hace de sus necesidades en los consejos y grupos de trabajo impulsados por Tonucci, en atención al artículo 12 de la Convención de la Organización de las Naciones Unidas (ONU) de los Derechos del Niño².

\subsection{La promoción de Ciudades Amigas de la Infancia por UNICEF}

El principal organismo internacional involucrado en la defensa de los derechos de la infancia converge con las ideas de Tonucci desde el momento en que identifica la garantía social y jurídica de protección y atención a la infancia con la promoción de su autonomía. Desde UNICEF se entiende que el desempeño autónomo y el ejercicio responsable de sus derechos facilita la construcción de una percepción positiva de control sobre su desarrollo físico, mental, espiritual, moral, psicológico y social (UNICEF COMITÉ ESPAÑol, 2009, 2017).

En un contexto de acelerada urbanización de las sociedades globales, al tiempo que de crecientes competencias y responsabilidad de los municipios sobre la calidad de vida de sus ciudadanos en el

particular al niño oportunidad de ser escuchado, en todo procedimiento judicial o administrativo que afecte al niño, ya sea directamente o por medio de un representante o de un órgano apropiado, en consonancia con las normas de procedimiento de la ley nacional." (UnICEF Comité EsPAÑOL, 2015). 
marco de la descentralización administrativa, se concibe la iniciativa Alcaldes defensores de los niños en 1991, a propuesta del Director Ejecutivo del UNICEF. Esta iniciativa impulsa el ámbito local como el espacio administrativo más idóneo para ejecutar políticas y planes integrales de promoción y defensa de los derechos de la infancia y la adolescencia, incluyendo su participación en los procesos de decisión. A lo largo de la década de los noventa surgieron redes de alcaldes implicados y a partir de 2000 se trasladó el compromiso al conjunto del municipio -ya no solo personalizado en la figura del alcalde-.

Se construirá en lo sucesivo el concepto de Ciudades Amigas de la Infancia, que será aplicable a cualquier sistema de gobierno local comprometido con la aplicación de la Convención sobre los Derechos del Niño, debiendo garantizar la capacidad de: a) participar activamente en la vida social e institucional, e influir en las decisiones a tomar respecto al modelo de localidad; b) disponer de servicios básicos sin riesgo de marginación, exclusión, violencia, explotación o abuso por motivo étnico, religioso, de género, socioeconómico y cultural; c) desplazarse y experimentar la localidad de manera autónoma para el juego y la relación con sus iguales; d) disfrutar de un entorno limpio y saludable, no contaminado, dotado de zonas ricas en vegetación y fauna para el disfrute y aprendizaje (UNICEF COMITÉ EsPAÑol, 2009).

La Ciudad Amiga de la Infancia coloca así a los niños en el centro de las políticas locales, constituyendo sus voces, necesidades, prioridades y derechos como un componente esencial de los proyectos y las decisiones. Además, impulsa alianzas entre los agentes responsables del cumplimiento de este compromiso (sociedad civil, asociaciones, escuela, empresas, organismos públicos, etc.), con apoyo en los Consejos de Infancia y Adolescencia.

Desde el punto de vista del modelo de la ciudad, el Sello de Reconocimiento Ciudad Amiga de la Infancia, con vigencia cuadrienal, exige el estudio de rasgos físicos, socio demográficos y funcionales de la localidad para su diagnóstico y la mejora de la planificación urbana. Se tienen en cuenta la evolución histórica del núcleo, las características de su población (composición, dinámica natural y migratoria, estructura socio-económica y laboral), las condiciones ambientales, la ordenación de los terrenos o la accesibilidad y la dotación de servicios (medios de transporte, cuerpos de seguridad, servicios sociales, culturales, educativos, sanitarios, etc.). Las dinámicas de trabajo y las propuestas derivadas se dirigen, en buena medida, a la adaptación de espacios y edificios públicos para personas con diversidad funcional, la regulación del tráfico, el control del impacto acústico y la contaminación ambiental, la mejora de la iluminación como elemento de seguridad, la dotación de transporte público debidamente adaptado a la demanda ciudadana en horarios e itinerarios, la proliferación de espacios y corredores con áreas verdes, o la programación de actividades, talleres y espectáculos en el espacio público, entre otros aspectos (PLATAFORMA DE INFANCIA \& UNICEF COMITÉ Español, 2018; Programa Ciudades Amigas de la Infancia UNICEF EsPAÑA, 2013).

\subsection{Propuesta de estándares para un diseño urbano afín a la población infantil}

De acuerdo con los principios pedagógicos expresados y en atención a los planteamientos de los programas en favor de las necesidades de la infancia, se entiende que la concepción y el diseño de la ciudad deben incorporar rasgos capaces de promover una experiencia urbana asentada en la autonomía y la participación con el fin de favorecer el desarrollo completo de destrezas y capacidades. Han de ser ricos los escenarios propicios para la compresión y la conceptualización de procesos y fenómenos naturales, sociales y culturales. La ciudad ha de ser, en definitiva, un espacio inductor de intelecto, conciencia e identidad. De ahí la utilidad de identificar una serie de indicadores o estándares cualitativos que alimenten modelos urbanos deseables en aspectos funcionales, infraestructurales y ambientales. En este sentido, se recoge a continuación un listado de rasgos que han de caracterizar a las ciudades sensibilizadas con el aprendizaje y el desarrollo de niños y niñas, de acuerdo con los postulados de La Ciudad de los Niños y Ciudades Amigas de la Infancia:

- Distribución equilibrada de usos y funciones en el conjunto del tejido urbano.

- Dotación de servicios y equipamientos sociales, sanitarios, educativos, culturales y de seguridad conforme a las características demográficas.

- Proliferación de plazas y espacios no edificados de uso público con los tipos de instalaciones y actividades solicitados para la relación, el ocio y el esparcimiento.

- Dotación de infraestructura de alumbrado ajustada al uso del espacio.

- Existencia de una red conectada de parques, jardines y corredores verdes en el conjunto del área urbana y su franja periurbana. 
- Accesibilidad peatonal a través de una red de itinerarios ininterrumpidos conforme a la demanda y experiencia cotidiana.

- Atenuación de los flujos de tráfico generados por vehículos motorizados particulares.

- Disponibilidad de un sistema de transporte público combinado, flexible y sostenible.

\section{Identificando herramientas para una ciudad más propicia a la infancia: aproximación al urbanismo social, participativo y sostenible}

\subsection{Rasgos diferenciales de un nuevo enfoque para entretejer la ciudad}

Prestar atención al urbanismo social, participativo y sostenible como herramienta favorecedora del desarrollo de la infancia tiene sentido teniendo en cuenta algunos de sus fundamentos principales. Se plantea como alternativa a paradigmas urbanísticos que no han logrado revertir procesos de pérdidas económicas y otros aspectos, como la desigualdad, la vulnerabilidad, el desarraigo, la fractura social o la merma ambiental. Busca recuperar la ciudad como construcción colectiva y extender el campo de la participación ciudadana frente al declive provocado por decisiones a menudo ajenas a la experiencia y a la voluntad del grueso de la población (Verdaguer \& VeLÁzQUez, 2012). Defiende la relevancia de las actividades cotidianas (productivas, domésticas, de desarrollo personal y comunitarias, comprendidas las lúdicas) como factor que ha de orientar la configuración de la ciudad (VALDIVIA \& al., 2017), incluida la regeneración de espacios degradados o en desuso (TRACHANA, 2012).

Se trata de un movimiento que crece en los inicios de este siglo, al tiempo que cristaliza la noción de desarrollo urbano sostenible en esferas institucionales globales y europeas. Y recoge, en cierto modo, la herencia de algunas experiencias de vínculo entre urbanismo y participación ciudadana conocidas en el último tercio del siglo pasado, en muchos casos apoyadas en una movilización vecinal sostenida por urbanistas y profesionales involucrados en el diseño urbano (BLANCAFORT \& REUS, 2016). Ahora se actualiza esta visión con la incorporación de pautas de trabajo, técnicas y métodos de nuestro tiempo. Destaca la importancia del proceso y del trabajo horizontal, desprovisto del principio jerárquico que otorga primacía a los agentes de la administración, con el fin de conceder protagonismo al espacio a proyectar y a cada grupo de actores de acuerdo con nuevas formas de relación, comunicación y movilización de nuestro tiempo, hoy con flujos más constantes y diversos debido a los cambios sociales y tecnológicos. Persigue, en definitiva, aprovechar una suerte de inteligencia colectiva que conduzca a mejores soluciones para la ciudad (DombLÁs, 2015; GRUPO DE ESTUDIOS Y Alternativas 21 -GEA21-, http://www.gea21.com/ archivo/urbanismo/; PaISAJE Transversal, 2012a, 2012b).

Es relevante el hecho de que esta corriente urbanística se concibe como producto de un consenso de ámbitos científicos y profesionales (arquitectura, ingeniería, geografía, sociología, derecho, economía, ecología...) interesados en diseñar un espacio urbano equitativo, integrado, sostenible y garante de calidad de vida. Interesa por elaborar diagnósticos y proponer soluciones creativas e innovadoras, a la vez que económicamente realistas y flexibles, a las oportunidades y problemas de la ciudad con la participación conjunta de actores institucionales, profesionales, científicos, económicos y sociales, incluyendo entes privados y públicos (coordinando a sus distintos departamentos), colectivos asociativos y ciudadanos individuales, mediante el desarrollo conjunto de espacios y dinámicas para el diálogo, el debate y la negociación ${ }^{3}$.

La atención se centra en aspectos como el diseño del espacio público, la adecuación de los modelos constructivos, la dotación de equipamientos, la regeneración del tejido urbano, la eficiencia energética, la integración social, la reactivación económica, la rehabilitación del patrimonio, la atenuación de impactos ambientales, la accesibilidad, la eliminación de barreras y la movilidad, entre otros. Una de las críticas que han recibido el urbanismo y la planificación urbana contemporánea es que, en la inmensa mayoría de los casos, cumple con las exigencias legales y técnicas recogidas en las distintas legislaciones urbanísticas, pero en muy pocas ocasiones se tienen en cuenta a los usuarios de los espacios urbanos cuando se diseñan, algo que es muy evidente en el caso de los espacios verdes urbanos (GómEZ-GonçALVES \& SÁnCHEZ \& Ceballos, 2018; Puyuelo \& Gual \& Galbis., 2005). Por tanto, en este nuevo urbanismo las intervenciones se abordan desde una metodología

${ }^{3}$ Para optimizar este método y dotarle del necesario equilibrio y de equidad, en ocasiones se introduce la figura del mediador, 
participativa basada en el desarrollo de mesas de trabajo, foros, talleres y actividades para percibir puntos de vista, intereses y prioridades de las personas implicadas en el uso y disfrute del espacio, consiguiendo promover procesos de transformación más transparentes (FIGS. 4 y 5); a lo que contribuyen la difusión de información y la concienciación como factores conducentes a que el ciudadano conozca el proyecto de ciudad, se identifique, participe, se apropie del espacio y compruebe el cumplimiento de lo proyectado, más allá del tradicional trámite de información pública y respuesta a alegaciones que se ha revelado insuficiente para incorporar la participación ciudadana (BLANCAFORT \& Reus, 2016; FRANK, 2006; GEA21, http://www.gea21.com/archivo/urbanismo/; Paisaje Transversal, 2012a, 2012b, 2019; https://paisajetransversal.com/).
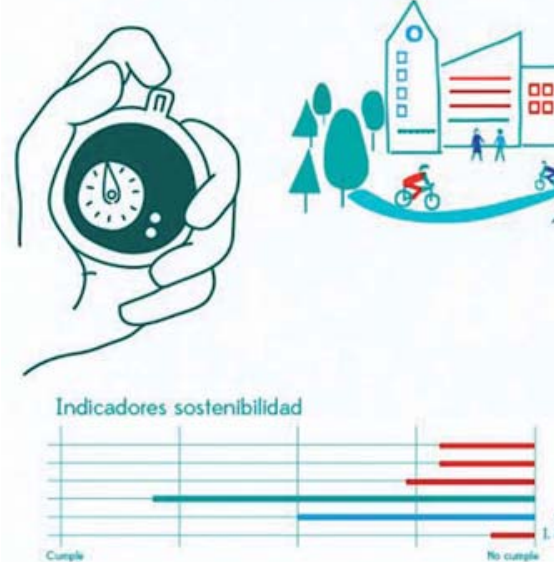

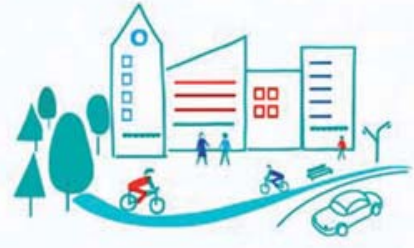

\section{INPAR}

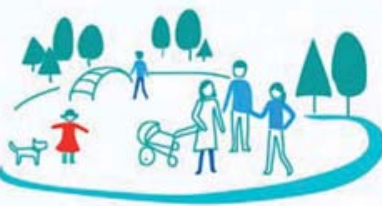

Espacio Público
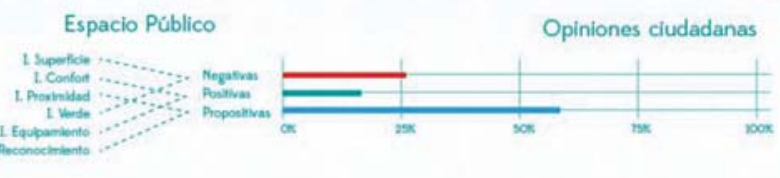

FIG. 4/ Esquema sintético de la herramienta Indicadores Participativos (INPAR) empleada por el equipo de Paisaje Transversal.

Fuente: Paisaje Transversal, https://paisajetransversal.com/.

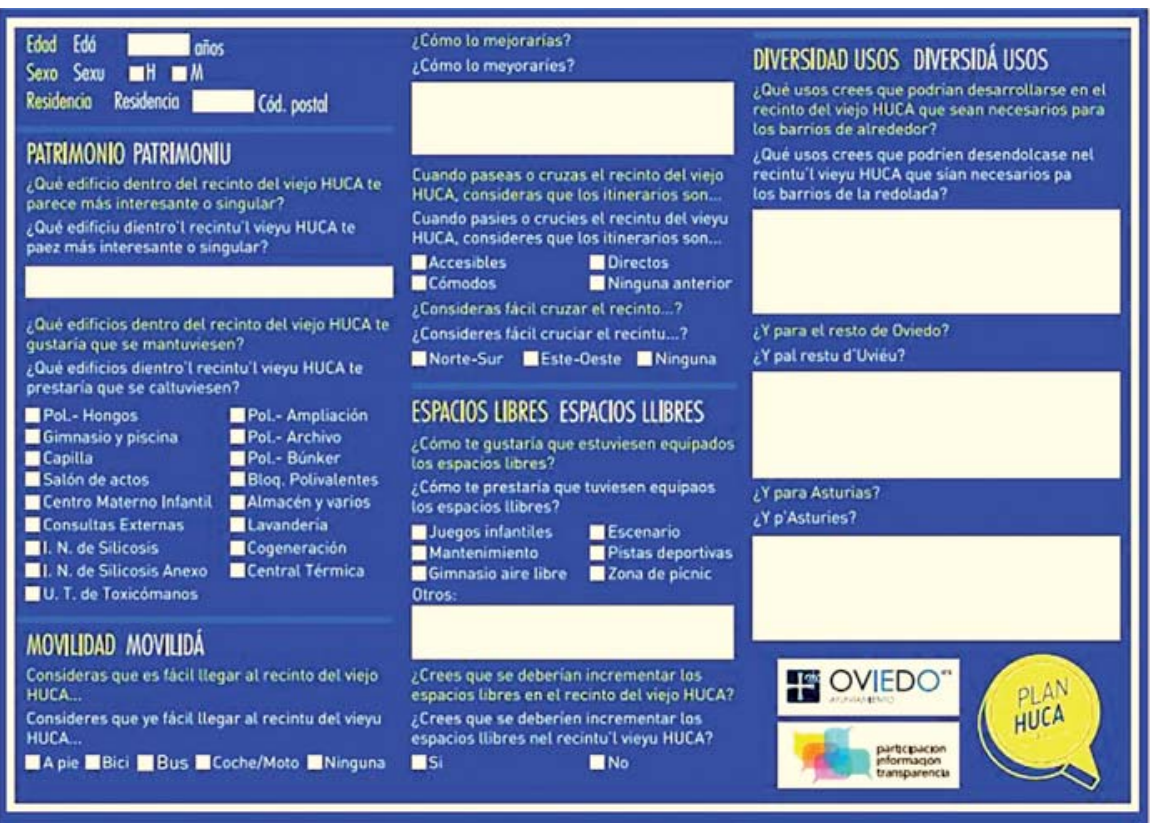

FIG. 5. Reproducción de los documentos elaborados para la campaña de información, consulta y participación ciudadana sobre la renovación del espacio de la antigua ciudad sanitaria de Oviedo.

Fuente: Paisaje Transversal, https://paisajetransversal.com/. 


\subsection{Proyectos creativos en}

\section{la verificación de una corriente con valor ciudadano añadido}

La valoración positiva del urbanismo social, participativo y sostenible en la perspectiva de una recualificación de la ciudad conforme a las determinaciones de Tonucci y UNICEF implica asimismo la revisión de planteamientos y resultados de algunos proyectos clave con el fin de observar si se contemplan rasgos urbanos alineados con los indicadores señalados más arriba.

Partiendo de aspectos generales funcionales, el urbanismo social, participativo y sostenible encuentra beneficio en plantear una vocación diversa para cada tramo del tejido urbano, traducida en una distribución equilibrada de usos del suelo, acompañada de una dotación de servicios y equipamientos ajustados a la demanda de cada núcleo. Somete a crítica el carácter monofuncional limitante de las áreas residenciales no centrales y considera básica una línea estratégica de reactivación y diversificación económica para cualquier sector urbano (ensayada notablemente, por ejemplo, en la regeneración urbana participativa en el barrio Virgen de Begoña, Madrid -Fıg. 6-, por Paisaje Transversal, 2012a). La reactivación pasa por el refuerzo de la identidad gremial, la formación y el reciclaje profesional para la mejora de la competitividad, así como por la rehabilitación del tejido degradado para su repoblación a través de la ayuda a la creación de nuevos negocios, además de infraestructuras y equipamientos con servicios públicos (véase el ejemplo de Estrategia de Desarrollo Urbano Sostenible e Integrado -EDUSI- del Cabanyal -Canyamelar- Cap de França por Va Cabanyal!, de 2016, ejemplo icónico por la intervención ciudadana). Esta corriente cuestiona, por tanto, la jerarquización y la limitación de usos según áreas urbanas y se fija en la distancia de los lugares de residencia a los equipamientos básicos y a los espacios comunitarios ("entorno equipado" y "entorno comunitario", por Col.lectiu Punt 6, como sustento de su auditoría de seguridad urbana con perspectiva de género).

Las mismas nociones de "entorno equipado" "y "entorno comunitario" conllevan la percepción del espacio público como entorno de convivencia, intercambio, debate y juego (FIG. 7). Defienden un entorno público abierto dotado de mobiliario, elementos vegetales y pavimentos pensados para un uso diverso cotidiano que fortalezca la pertenencia a la comunidad y la red social en contacto directo, frente a la emergencia de la esfera virtual; a lo que ha de contribuir una concepción estética que agrade, genere identificación y atraiga a la población (VALDIVIA \& al., 2017). También se conocen experiencias de urbanismo participativo para la mejora del aprovechamiento

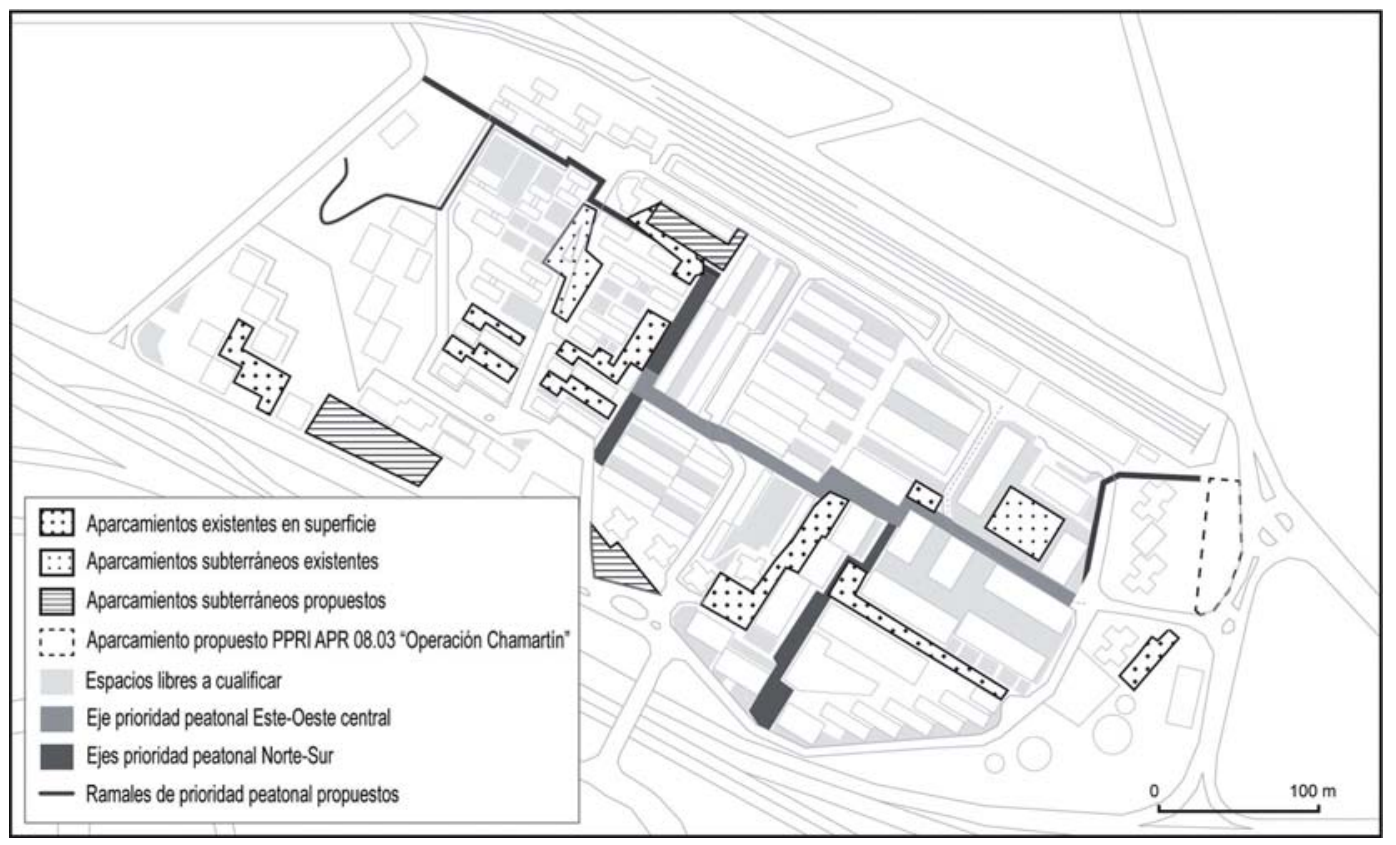

FIG. 6/ Recualificación del espacio en el proceso de regeneración urbana participativa del barrio Virgen de Begoña. Elaboración propia a partir del plano original.

Fuente: Paisaje Transversal, http://paisajetransversal.com/portfolio/eje-de-accesibilidad-vdb/ 

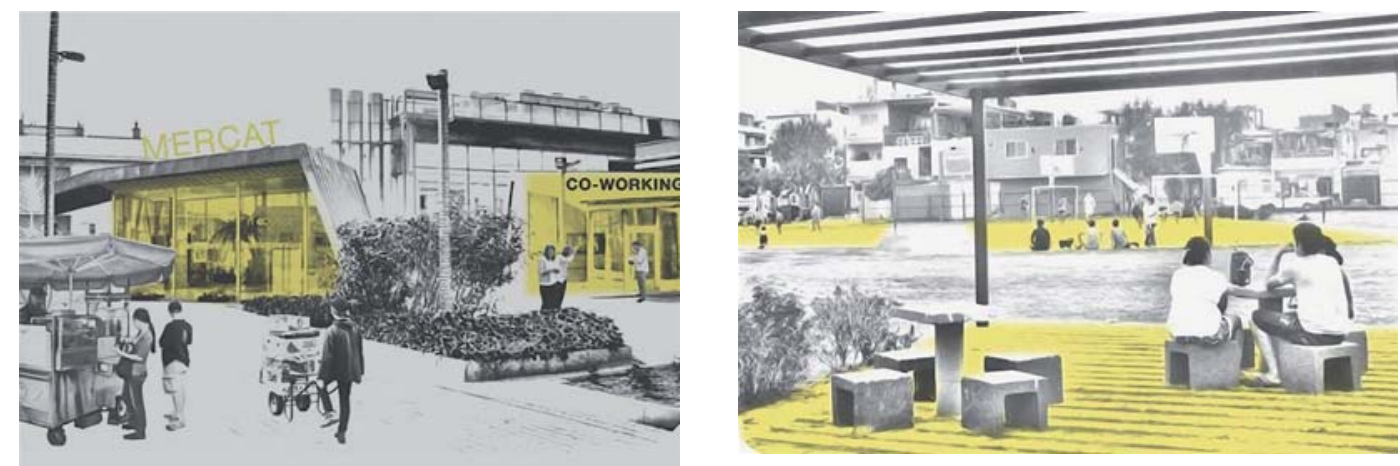

FIG. 7 a y 7 b/ Infografias expresivas de los conceptos "entorno equipado" y "entorno comunitario" que subrayan la dotación de mobiliario, elementos vegetales y equipamientos para un uso cotidiano y la construcción de una identidad comunitaria. Reproducción de los originales elaborados por A. Molina para Col.lectiu Punt 6.

Fuente: VALDIVIA \& al., 2017.

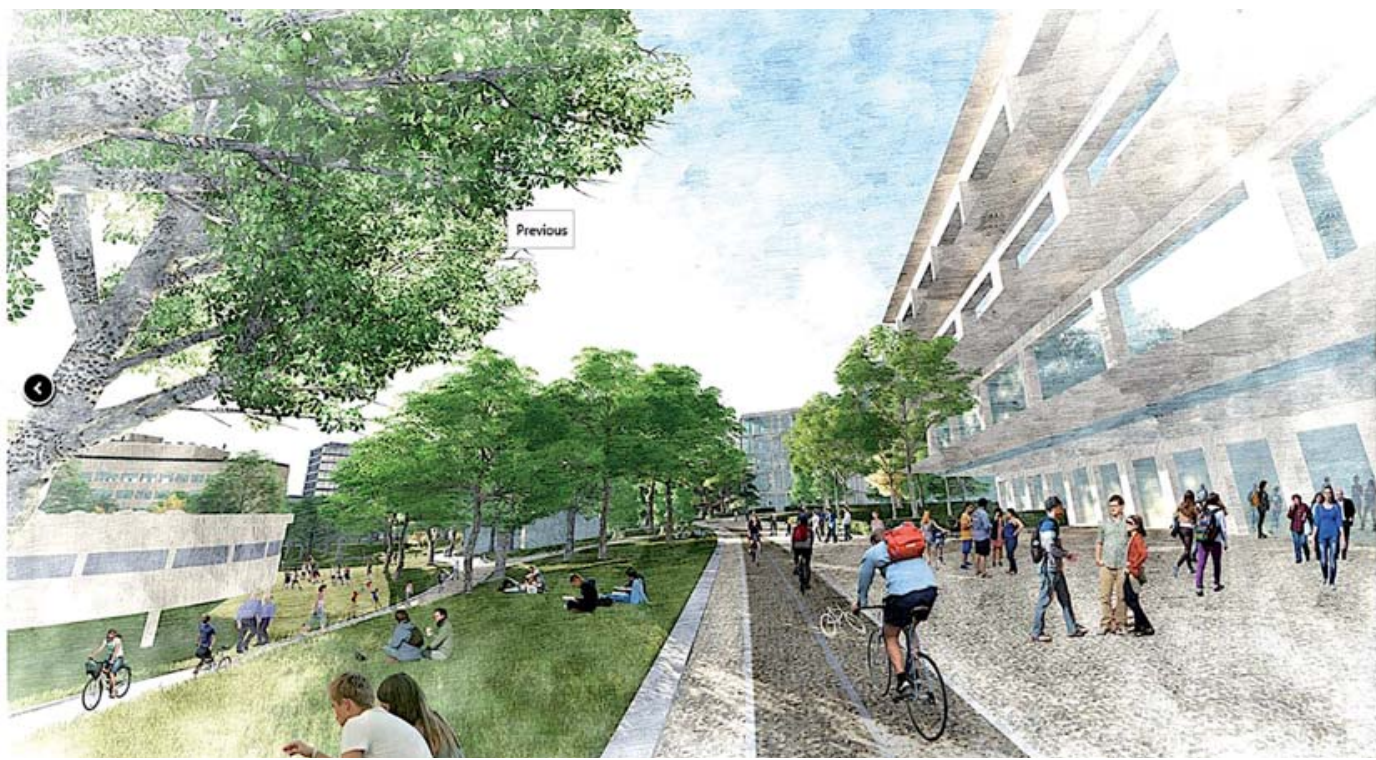

FIG. 8/ Interpretación del espacio en la ordenación del ámbito del antiguo Hospital Central de Asturias (HUCA) en El Cristo-Buenavista de Oviedo.

Fuente: reproducción del original elaborado por Juan Tur, Alexandra Delgado y Daniel Cortizo, HUCAMP Arquitectos, reproducido en http://www.arquitecturaviva.com/es/Info/News/Details/11414.

del espacio abierto protagonizadas por niños, en relación con el mobiliario óptimo y con los usos permitidos, como el proyecto Solar en el barrio de La Soledad de Palma de Mallorca (Arquitectives, https://www.arquitectives.com/solar).

En la dimensión estética participa la iluminación, que puede reforzar la consideración positiva del conjunto urbano, pero a la vez ha de asistir a la ciudadanía en el uso del espacio y, en nuestro tiempo, respetar el criterio de la eficiencia energética. Es significativa, en esta línea, la experiencia piloto del proyecto Córdoba LUZe en el barrio de
Axerquía Norte, acometido por impulso municipal en 2014 con la participación de las empresas Creara, Inersur, Aureolighting y del colectivo profesional Paisaje Transversal. Se ha basado en la incorporación de lámparas eficientes y en el estudio de ubicaciones óptimas para favorecer la visibilidad de señalizaciones y de recodos de la vía pública especialmente frecuentados o que requieren una mejora de la habitabilidad y de la seguridad. También se ha destinado a reducir el alumbrado donde no es tan necesario (PAISAJE TRANSVERSAL, https://paisajetransversal.com/portfolio/ambienteurbano-nocturno-cordoba-luze/). 


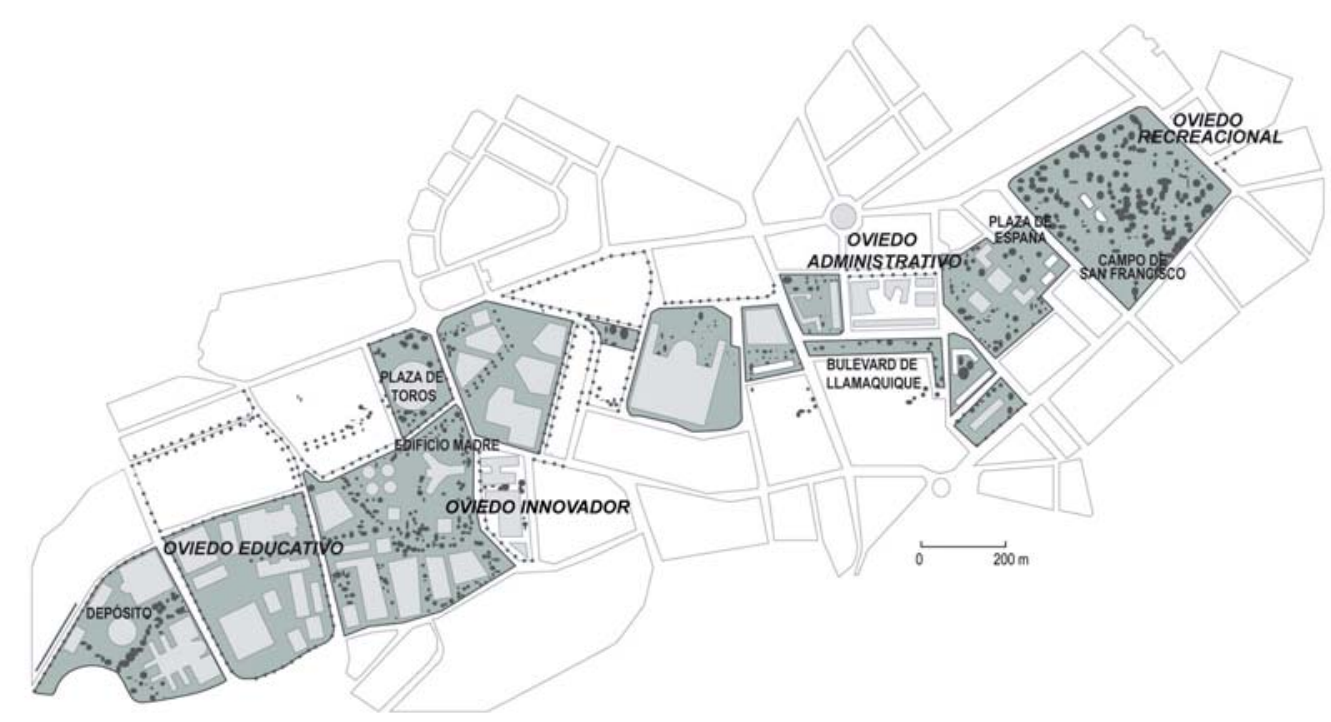

FIG. 9/ Plano del corredor verde propuesto por HUCAMP! para conectar la antigua ciudad sanitaria de Oviedo con el centro urbano.

Fuente: Tur, Delgado \& CoRtizo, 2019.

Una habitabilidad renovada pasa, por otro lado, por un reencuentro de la dinámica urbana con elementos territoriales de dominante rural y natural; es decir, por la proliferación de parques, jardines y huertos e incluso por su interconexión a través de corredores tanto en la ciudad compacta como en la franja periurbana, dadas sus repercusiones positivas en esferas variadas como la gestión ambiental y la restauración ecológica, la educación, la promoción del ocio saludable, la integración socio-laboral, etc. Son aspectos analizados por el Centro de Estudios Ambientales de Vitoria-Gasteiz (El espacio agrícola entre la Ciudad y el Campo. Desarrollo de un Catálogo de Buenas Prácticas Urbanas con Criterios de Sostenibilidad) para consolidar el denominado Anillo Verde vitoriano, promovido por numerosas entidades y asociaciones (Gobierno Vasco, 2003; Verdaguer, 2013).

El espacio verde es clave no solo en operaciones periurbanas sino también de reforma interior como la promovida para la ordenación del ámbito del antiguo Hospital Central de Asturias (HUCA) en el distrito El Cristo-Buenavista de Oviedo. El proyecto HUCAMP!, seleccionado previa convocatoria de un concurso internacional en 2017 , vincula el objetivo de regeneración a la habilitación de una gran campa como elemento central y organizador de usos en un distrito evocador del rico entorno rural asturiano, en el que el ciudadano puede satisfacer en plena ciudad el disfrute de valores paisajísticos y ambientales (TUR \& DELGADO \& CORTIZO, 2019). Más allá, partiendo de la propia campa, se plantea un corredor con senda para la movilidad peatonal y ciclista que busca una nueva conectividad con el centro histórico y con distritos renovados del norte de Oviedo, encadenando zonas verdes y espacios abiertos que favorecen la continuidad en el tránsito (FIGs. 8 y 9).

En esta línea que concibe HUCAMP!, se conoce un completo proyecto de promoción de la movilidad peatonal impulsado por el Ayuntamiento de San Sebastián, denominado Donostia Camina, que diseña una red de itinerarios peatonales seguros y ambientalmente cuidados para la interconexión de las diferentes zonas (SANZ, s.f.). Se debe añadir que la facilidad para un desplazamiento peatonal seguro en itinerarios cotidianos es un asunto del que se conocen, además, acciones de colectivos urbanistas inspiradas directamente por Tonucci y otros investigadores dedicados a promover la movilidad infantil (ver FIG. 10). Sirvan de ejemplo las analizadas en la guía Camino Escolar. Pasos hacia la autonomía infantil por GEA21 (RomÁn \& SALís, 2010), por ejemplo, en Barcelona, en Granollers, en San Sebastián, en Zarauz, en Madrid... O la que promueve el Servei Catalá de Trànsit con la asistencia técnica del propio gabinete de GEA21: Els camins escolars (Servel CATALÁ de Transit, 2016).

El control espacial de la contaminación ambiental, la aminoración del impacto acústico y la apuesta por la sostenibilidad llegan asimismo de la mano de los sistemas de transportes combinados, flexibles y no contaminantes. O de la atenuación de tráficos motorizados y el fomento de la movilidad "blanda", complementarios de las cuestiones anteriores, de 


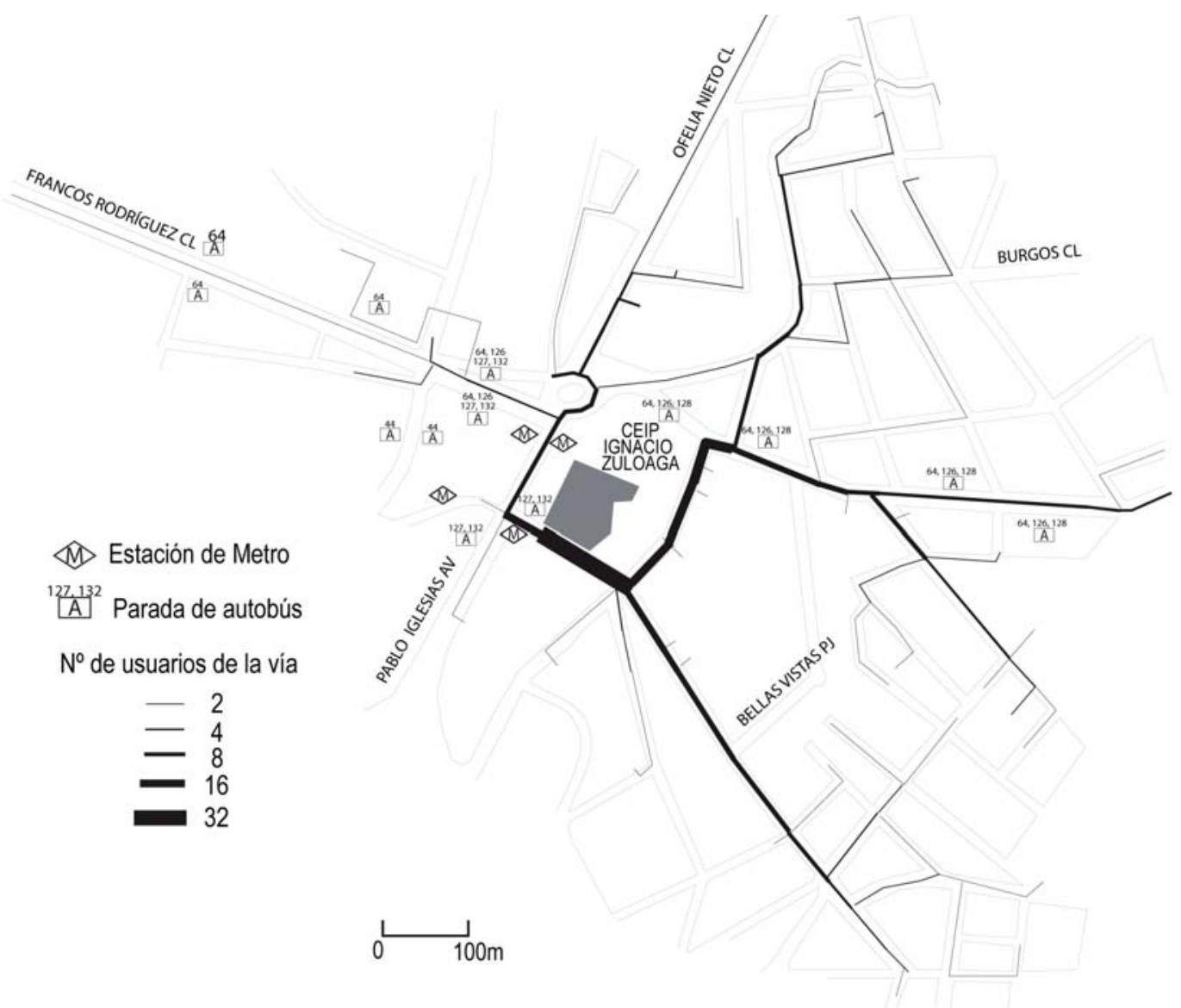

FIG. 10/ "Araña de movilidad" del Colegio Ignacio Zuloaga (proyecto Madrid a pie, Camino Seguro al Cole).

Sobre las rutas más utilizadas se prevé el calmado del tráfico (cambios de pavimentos, ensanche y continuidad de aceras sobre intersecciones). Elaborado a partir del original de la Dirección General de Movilidad de Madrid.

Fuente: RomÁn \& SALIS, 2010..

las que el proyecto de ecobarrio de Trinitat Nova, en Barcelona, coordinado por GEA21 con las consultorías Aiguasol, Ecoinstitut e Idees, ofrece medidas representativas: accesibilidad intermodal, incorporación a red de itinerarios ciclistas preexistente, restricción de la velocidad para el tránsito motorizado, construcción de plataformas y pasos elevados para evitar barreras a la movilidad peatonal (GAFFRON \& HUISMANS \& SKALA, 2008). También merecen reseña los catálogos de buenas prácticas en la movilidad al trabajo vinculados a la experiencia de planes de movilidad sostenible en empresas: sistemas de información actualizada para la elección de alternativas óptimas, incentivos y ayudas al uso de transportes alternativos, servicio de vehículos compartidos y/o colectivos con rutas adaptadas, flexibilización de la jornada laboral son algunas de las medidas que favorecen una dinámica urbana más amable (VEGA, 2005, 2006).

\section{A modo de conclusión: una concepción urbana emergente en contextos de desafío comunitario y global}

El análisis realizado reafirma la consideración en favor del urbanismo social, participativo y sostenible como una alternativa válida para recuperar la ciudad como espacio para la infancia, dados la definición y el cumplimiento de objetivos convergentes con los estándares cualitativos elaborados a partir de los planteamientos de Tonucci y UNICEF. En efecto, las prioridades de los agentes impulsores del paradigma urbanístico aquí presentado vienen a encontrarse con las establecidas por los programas internacionales defensores de la infancia; una perspectiva que merece ser tenida en cuenta por las entidades locales 
para una recualificación de la ciudad en su dimensión física y de ordenación de usos y actividades, teniendo en cuenta, además, el reto de alcanzar las metas de la Agenda 2030 y los Objetivos del Desarrollo Sostenible aplicados al ámbito urbano. Obsérvese que estas metas y objetivos se alinean, en buena medida, con las razonables prioridades ya referidas (Gobierno de España, https://www. agenda2030.gob.es/objetivos; ONU,https://www. un.org/sustainabledevelopment/es/developmentagenda/). En cualquier caso, se revela adecuado el requerimiento firme a los municipios interesados en obtener certificaciones que avalen su sensibilidad hacia el desarrollo infantil, de optar por esta forma de intervención en la ciudad.

La elaboración del estudio con este planteamiento se ha orientado a realzar el emergente cambio de enfoque que se está produciendo en la manera de construir la ciudad, en el que es especialmente relevante el papel del planeamiento urbanístico como instrumento al servicio de los agentes territoriales. Ciertamente las ciudades de nuestro país y de los países de nuestro entorno se enfrentan a un contexto complejo: se solapan la concentración constante de población en áreas urbanas, la recuperación de una recesión económica grave y la necesidad de afrontar definitivamente un desafío ambiental que condicionará nuestro desarrollo futuro. En este sentido, presentar en el estudio experiencias emergentes españolas realizadas por equipos dotados de una conciencia ciudadana renovada como vía de contraste se ha revelado una decisión pertinente. Parece oportuno, además, que desde el ámbito académico y de la investigación se les preste atención como modo de contribuir a su visibilidad y como aval de cara a la sensibilización de los técnicos y gestores de la Administración.

Los retos de investigación futura han de encaminarse hacia el estudio de experiencias municipales particulares, en ciudades con características diferentes y que ocupan posiciones distintas dentro de la red urbana, con el fin de analizar la correlación entre tipos de intervención urbana y grado de cumplimiento de los objetivos en favor de la infancia. La perspectiva del presente trabajo merece, además, una profundización en aquella dimensión que se refiere a los modos de implementación de la participación infantil, respecto a la identificación y expresión de los problemas urbanos, al desarrollo de trabajo de campo y a la propuesta de cambios y formulación de soluciones creativas. Para ello, en un futuro se podrán tomar como referencia los estándares elaborados en este trabajo con el objetivo de tratar de evaluar las propuestas existentes dentro del movimiento urbanístico aquí analizado. Además, se podría profundizar más en cómo se han desarrollado las metodologías participativas en el diseño de los nuevos espacios urbanos y caracterizar con detalle el hilo común existente entre las experiencias con mejores resultados, de modo que pueda llegar a extrapolarse a otras ciudades.

Conviene mencionar asimismo que la forma de hacer ciudad que se ha analizado en este trabajo no es única ni incompatible con otros movimientos contemporáneos. Por ejemplo, a la base experiencial de los programas internacionales señalados, se puede sumar la de otros movimientos con impacto en tiempo reciente, como Nós Propomos! Cidadania e Inovação na Educação Geográfica, encabezado por un grupo de geógrafos portugueses y que se ha extendido por Portugal, Brasil, España, Colombia Perú y México, con aprovechamiento de sinergias entre universidades, ayuntamientos y escuelas (Rodríguez \& Claudino, 2018).

Asimismo, alineadas con la visión de ciudad afín a la infancia, las iniciativas ciudadanas guiadas por la superación de problemas comunitarios, de acuerdo con las necesidades y demandas de sus usuarios y apoyadas en las denominadas "prácticas económicas alternativas", como huertos urbanos, bancos de tiempo, centros sociales autogestionados, etc. (GómEZ-GonçALVES, 2019; SÁNCHEZ, 2019), constituyen otro objeto de estudio que puede presentar vínculos y rasgos compartidos con el tema aquí presentado. Con todo, reviste interés comparar su efecto con el de otras corrientes de intervención muy distintas, fundamentadas en la mercadotecnia territorial, que arrojan resultados llamativos en la mejora del disfrute urbano ante la búsqueda de una transformación de la ciudad como espacio experiencial atractivo.

\section{Bibliografía}

Alaparone, F.R. \& Rissotto, A. (2001): Children's Citizenship and Participation Models: Participation in Planning Urban Spaces and Children's Councils. Journal of Community and Applied Social Psychology, $11,421-434$.

Almers, E. \& Askerlund, P., \& KJellström, S. (2018): Why forest gardening for children? Swedish forest garden educators' ideas, purposes, and experiences. The Journal of Environmental Education, 49(3), 242-259. doi: 10.1080/00958964.2017.1373619

ARANDA, A. M. (2001): Identidad y educación ciudadana en contextos a escala Global. Aula: Revista De Pedagogía de la Universidad de Salamanca, 13, 37-50.

- (2010): Didáctica del conocimiento del medio social y cultural en Educación Infantil, Madrid, Síntesis Educación.

ARQuITECTIVES: Solar. Recuperado de: https://www. arquitectives.com/solar [consultado 05/09/2019]. 
ARQUITECTURAVIVA.Com: Tur, Delgado y Cortizo: reordenación urbana del HUCA. Recuperado de: http:// www.arquitecturaviva.com/es/Info/News/ Details/11414 [consultado 15/09/2019]

AsociaCIÓN DE VIANDANTES A PIE (2002): Entrevista con Francesco Tonucci. Boletín $C F+S$, 19, edición digital. Recuperado de: http://habitat.aq.upm.es/ boletin/n19/afton.html [consultado 01/08/2019].

BARTLETT. S \& al. (1999): Cities for Children: Children's Rights, Poverty and Urban Management, Londres, Earthscan Publications for UNICEF.

https://www.amazon.com/s?i=stripbooks\&rh=p 27 \%3ASheridan+Bartlett\%3BRoger+Hart\%3BDavid +Satterthwaite\%3BXimena+de+la+Barra\%3BAlfre do+Missair\&s=relevancerank\&lanquage $=$ es\&text $=$ Sheridan+Bartlett\%3BRoger+Hart\%3BDavid+Satt erthwaite\%3BXimena+de+la+Barra\%3BAlfredo+M issair\&ref $=$ dp byline $\mathrm{sr}$ book 1

BLANCAFORT, J. \& ReUs, P. (2016): "Los orígenes de la participación ciudadana en el urbanismo contemporáneo". En J. BLANCAFORT \& P. Reus (Coords.) La participación en la construcción de la ciudad (pp. 44-59), Cartagena, Universidad Politécnica de Cartagena.

Boyden, J. \& Holden, P. (1991): Children of the Cities, Londres, Zed Books.

CAlle, M. \& al. (2008): "La formación en didáctica de las ciencias sociales del maestro de Educación Infantil. Una propuesta adaptada al espacio europeo de educación superior". En R.M. ÁviLA, M.A \& Cruz M.C \& Diez (Coords.), Didáctica de las ciencias sociales, currículo escolar y formación del profesorado [recurso electrónico]: La didáctica de las ciencias sociales en los nuevos planes de estudio (pp. 113-134), Jaén, Universidad de Jaén, Servicio de Publicaciones.

Cañal, P. \& Garcia-Carmona, A. \& Cruz-Guzmán, M (2016): Didáctica de las Ciencias Experimentales en Educación Primaria, Madrid, Paraninfo.

CHAWLA, L. (2015): Benefits of nature contact for children. Journal of Planning Literature, 30(4), 433-452.

CLEMENTS, R. (2004): An investigation of the status of outdoor play. Contemporary Issues in EarlyChildhood, 5(1), 68-80.

CuencA, J. M. (2011): "Concepciones del alumnado en educación infantil para la comprensión de medio sociocultural: Papel de las experiencias y el aprendizaje lúdico". En M.P. RIVERo (Coord.), Didáctica de las ciencias sociales en educación infantil (pp. 111-129), Zaragoza, Mira Editores.

Diaz, E.M. \& Rodriguez, I. (2003): "Las secuelas de la ciudad negocio: los parques urbanos de Madrid". En L. López, C.E \& ReleA \& J. Somoza (Eds.), La ciudad: nuevos procesos, nuevas respuestas (pp. 193-204), León, Secretariado de Publicaciones y Medios Audiovisuales.

Domblás, U. (2015): Socialization, Learning And Perception Of Urban Landscape: The Case Of Estella-Lizarra. WIT Transactions on The Built Environment, 153, 841-851.

DRISKELL, D. (2002): Creating better cities with children and youth: a manual for participation, París, Londres, Earthscan, UNESCO.

Dyment, J.E. (2005): Green School Grounds as Sites for Outdoor Learning: Barriers and Opportunities.
International Research in Geographical and Environmental Education, 14(1), 28-45.

EuRostat (2016): Urban Europe-statistics on cities, towns and suburbs-executive summary. Recuperado de: https://ec.europa.eu/eurostat/statistics-explained/index.php/Urban Europe - statistics on cities, towns and suburbs - executive summary [consultado el 1 de diciembre de 2019].

FERNÁNDEZ, G. \& FERNÁNDEZ, V. (2019): "La construcción de la ciudad a lo largo de la historia (II): la ciudad industrial". En G. FERnÁNDEZ, Atlas de Geografía Humana de España (pp. 397-447), Madrid, Paraninfo.

FRANK, K.I. (2006): The potential of Youth Participation in Planning. Journal of Planning Literature, 20(4), 351-371.

Freeman, C. \& Tranter, P. (2011): Children and their urban environment: changing worlds, London y Washington D.C., Earthscan.

FREIRE, H. (2011): Educar en verde. Ideas para acercar a niños y niñas a la naturaleza, Barcelona, Graó.

Gaffron, P. \& Huismans, G. \& Skala, F. (Coords.) (2008): Proyecto Ecocity. Manual para el diseño de ecociudades en Europa, Libro I, Bilbao, Bakeaz, GEA21.

Garcia-González, M. C., \& Guerrero, S. (2019): Sobre el espacio de juego infantil en la ciudad moderna: Lady Allen of Hurtwood versus Jakoba Mulder. Ciudad y Territorio Estudios Territoriales (CyTET), 51(200), 311-326.

GEA21: Quiénes somos. Recuperado de: http://www.gea21.com/quienes-somos/ [consultado 15/09/2019].

GEA21: Urbanismo. Recuperado de: http://www.gea21.com/archivo/urbanismo/ [consultado 15/09/2019].

Giles-Corti, B. \& al (2011): School site and the potential to walk to school: The impact of street connectivity and traffic exposure in school neighborhoods. Health \& Place, 17, 545-550.

GILL, T. (2014): The benefits of children's engagement with nature: A systematic literature review. Children Youth and Environments, 24(2), 10-34.

Gobierno de España. Agenda 2030: Objetivos de Desarrollo Sostenible. Recuperado de: https://www.agenda2030.gob.es/objetivos [consultado 20/09/2019]

Gobierno VAsco (2003): Criterios de sostenibilidad aplicables al planeamiento urbano, Serie Programa Marco Ambiental no 23, Bilbao, Departamento de Ordenación del Territorio y Medio Ambiente, Sociedad Pública de Gestión Ambiental.

Gómez, A. (2013): Localización y acceso al verde urbano de la ciudad de Salamanca. Boletín de la Asociación de Geógrafos Españoles, 63, 125-145.

Gómez-GonçALVEs, A. (2019): "Huertos urbanos: laboratorios para la enseñanza y el aprendizaje práctico de la alternatividad". En J.L. SÁnchez (Coord.), Espacios y prácticas económicas alternativas en las ciudades españolas (pp. 87-106), Cizur Menor (Navarra), Thomson Reuters Aranzadi.

- \& Corrochano Fernández, D. (2018): El uso de los espacios verdes urbanos como recurso didáctico en el aula de Educación Primaria. En A. GARCíA DE LA VEGA (Ed.), Contribución didáctica al aprendizaje de la geografía (pp. 641-649). Universidad 
Autónoma de Madrid y Asociación de Geógrafos Españoles.

- Sánchez, J.L. \& Ceballos, A. (2018): El impacto de las políticas de austeridad en los espacios verdes urbanos según la percepción de los usuarios. Estudio de caso en tres ciudades españolas. Boletín de la Asociación de Geógrafos Españoles, 77, 398-427.

Hernández, C. (1986): Los valores sociales, un instrumento para el conocimiento social del niño: Su reflejo en la comunicación publicitaria. Infancia y Aprendizaje. Journal for the Study of Education and Development, 35, 109-122.

HerRmann, M. G. (2016): Instrumentos de planificación y diseño urbano para promover al peatón en las ciudades. Un estudio comparado entre Chile y Alemania. Revista Urbano, 34, 48-57.

KENIGER, L. \& al (2013): What are the benefits of interacting with nature? International journal of environmental research and public health, 10(3), 913-935.

LIN, E-Y. \& al. (2017): Social and built-environment factors related to children's independent mobility: The importance of neighbourhood cohesion and connectedness. Health \& Place, 46, 107-113.

Lopes, F. \& CordoviL, R. \& Neto, C. (2014): Children's independent mobility in Portugal: effects of urbanization degree and motorized modes of travel. Journal of Transport Geography, 41, 210-219.

Malberg Dyg, P., \& Wistoft, K. (2018): Wellbeing in school gardens - the case of the Gardens for Bellies food and environmental education program. Environmental Education Research, 24(8), 1177-1191. doi: 10.1080/13504622.2018.1434869

Maller, C. \& ToWnsend, M. (2006): Children's mental health and wellbeing and hands-on contact with nature. International Journal of Learning, 12(4), 359-372.

MARTiNEz, M. (2004): Entrevista a Francesco Tonucci. Autor de Cuando los niños dicen basta. Educación y biblioteca, 139, 29-34.

MINISTERIO DE EDUCACIÓN Y CIENCIA (2006): Real Decreto 1630/2006, de 29 de diciembre, por el que se establecen las enseñanzas mínimas del segundo ciclo de Educación infantil. Boletín Oficial del Estado, 4, jueves 4 de enero de 2007, 474-482.

- (2007): Orden ECI/3960/2007, de 19 de diciembre, por la que se establece el currículo y se regula la ordenación de la Educación Infantil. Boletín Oficial del Estado, 5, jueves 5 de enero de 2008, 1.0161.036.

Ministerio de Educación, Cultura y Deporte (2014): Real Decreto 126/2014, de 28 de febrero, por el que se establece el currículo básico de Educación Primaria. Boletín Oficial del Estado, 52, sábado 1 de marzo de 2014, 19.349-19.420.

NavarRo, V. (2013): Playgrounds del siglo XXI: Una reflexión sobre los espacios de juego de la infancia. Arquitectonics: Mente, Territorio y Sociedad, 25, 189-202.

ONU: Objetivos de Desarrollo Sostenible. Recuperado de: https://www.un.org/sustainabledevelopment/es/ development-agenda/ [consultado 20/09/2019]

PaISAJe Transversal: Córdoba Luze Ambiente Nocturno. Recuperado de: https://paisajetransversal.com/ portfolio/ambiente-urbano-nocturno-cordoba-luze/ [consultado 13/12/2020]
Paisaje Transversal: Eje de Accesibilidad VDB. Recuperado de: http://paisajetransversal.com/ portfolio/eje-de-accesibilidad-vdb/ [consultado 05/09/2019]

Paisaje Transversal: Hacemos. Recuperado de: http://paisajetransversal.com/concepto/ [consultado 01/09/2019]

Paisaje Transversal: Somos. Recuperado de: http://paisajetransversal.com/oficinal [consultado 01/09/2019]

Paisaje Transversal (2012a): A participar se aprende participando. VdB; Acción y reflexión críticas en el proyecto para la regeneración urbana participativa en el barrio Virgen de Begoña (Madrid). Hábitat y Sociedad, 4, 15-31.

Paisaje Transversal (2012b): Nuevos tiempos, nuevas estrategias: Hacia una metodología urbana en beta permanente. Revista La Ciudad Viva, 6, 1-4.

- (2019): Escuchar, co-crear y transformar la ciudad colectivamente". Ciudad sostenible, resiliente e innovadora, 36, 17-22.

Plataforma de Infancia \& UNICEF Comité Español (2018): Manifiesto de Oviedo, Madrid, UNICEF Comité Español.

Programa Ciudades Amigas de la Infancia UNICEF España (2013): La ciudad que queremos: una ciudad amiga de las personas, Madrid, UNICEF Comité Español.

Puyuelo, M., Gual, J. \& Galbis, M. (2005): Espacios abiertos urbanos y personas mayores: una experiencia llevada a cabo en distintos parques de la ciudad de Castellón sobre el diseño y su interacción con la población anciana, Castellón de la Plana, Universitat Jaume I.

Rissotto, A. \& TonUCCI, F. (2002): Freedom of movement and environmental knowledge in elementary school children. Journal of Environmental Psychology, 22, 65-77.

Rodriguez, M.A. \& Claudino, S. (2018): Nosotros proponemos. Ciudadanía, sostenibilidad e innovación geográfica ante los desafíos educativos de la sociedad, Barcelona, Editorial Graó.

Román, M. \& Salís, I. (2010): Camino escolar. Pasos hacia la autonomía infantil, Madrid, GEA21 Grupo de Estudios y Alternativas.

Sánchez, J.L. (Coord.) (2019): Espacios y prácticas económicas alternativas en las ciudades españolas, Cizur Menor (Navarra), Thomson Reuters Aranzadi.

Sanz, A. (s.f.): Donostia camina. Pasos de una estrategia. Proyectos y propuestas para el peatón en San Sebastián, San Sebastián, Gabinete de Prensa, Publicidad y Publicaciones, Ayuntamiento de San Sebastián.

SEgoviA, C. (2017): La vida de la infancia en la ciudad y su conflicto con el mundo adulto. Kultur: revista interdisciplinària sobre la cultura de la ciutat, 4(8), 149-168.

Servel Catalá de Transit (2016): Els camins escolars, Dossier técnic de seguretat viària no 27, Barcelona, Generalitat de Catalunya, Departament d'Interior.

SeVILLA, J. (2014): "Una propuesta didáctica en el entorno urbano para la formación en valores en Educación Infantil". En J. Pagès \& A. Santisteban (Eds.), Una mirada al pasado y un proyecto de futuro. Investigación e innovación en didáctica de las ciencias sociales (pp. 107-118), Barcelona, Universidad Autónoma de Barcelona. 
SiMONE, M. \& ESTEVES, M. (2017): O espaço público e o lúdico como estratégias de planejamento urbano humano em: Copenhague, Barcelona, Medellín e Curitiba. Cadernos Metrópole, 19(39), 635-663.

Spencer, C. \& Blades, M. (2005): Children and Their Environments: Learning, Using and Designing Spaces, Cambridge, University Press.

TEY, A. \& CIFRE-MAS, J. (2011): El profesorado ante el reto del aprendizaje ético y el desarrollo de las competencias sociales y ciudadanas. El modelo adoptado en el programa Barcelona, Aula de Ciutadania. Revista De Educación, 1, 225-242.

TonucCl, F. (1994): La ciudad de los niños. Cuadernos de Pedagogía, 229, 8-12.

- (2009): Ciudades a escala humana: La ciudad de los niños. Revista De Educación, 1, 147-168.

- (2009): ¿Se puede enseñar la participación? ¿Se puede enseñar la democracia? Investigación en la escuela, 68, 11-24.

Trachana, A. (2012): Urbe ludens: espacios para el juego en la ciudad. Ciudad y Territorio Estudios Territoriales (CyTET), 44(173), 423-444.

TRILLA, J. (2005): La idea de ciudad educadora y escuela. Educación y ciudad, 7, 73-106.

TuR, J. \& Delgado, A. \& CoRtizo, D. (2019): HUCAMP! La campa de todos. Una apuesta por la regeneración urbana estratégica en Oviedo. Ciudad sostenible, resiliente e innovadora, 36, 62-66.

UNICEF Comité Español (2009): Pongamos a la infancia en la agenda política local. Manual básico para responsables políticos municipales, Madrid, UNICEF Comité Español.

- (2015): Convención sobre los derechos del niño, Madrid, UNICEF Comité Español.

- (2017): Participación infantil: marco clave del programa Ciudades Amigas de la Infancia, Madrid, UNICEF Comité Español.
VALDIVIA, B. \& al (2017): Entornos habitables. Auditoría de seguridad urbana con perspectiva de género en la vivienda y el entorno, Barcelona, Col.lectiu Punt 6.

Vega, P. (2005): El transporte al trabajo. Planes de movilidad sostenible en empresas, Madrid, Instituto Sindical del Trabajo, Ambiente y Salud.

- (2006): Catálogo de buenas prácticas en la movilidad al trabajo, Madrid, Instituto Sindical del Trabajo, Ambiente y Salud.

VeRDAGUER, C. (2013): El campo y la ciudad, áreas de reencuentro. Hacia una Nueva Cultura del Territorio. Hábitat y sociedad, 6, 11-40.

— \& VelÁzQUez, I. (2012): La ciudad de abajo a arriba Aportaciones para la práctica y la teoría del urbanismo participativo. Hábitat y sociedad, 4, 7-11.

UNICEF Comité Español: Ciudades Amigas de la Infancia. Recuperado de: https://ciudadesamigas. org [consultado 15/08/2019]

Wells, N. \& Evans, G. (2003): Nearby Nature: A Buffer of Life Stress Among Rural Children. Environment and Behavior, 35(3), 311-330.

\section{Abreviaturas}

CNR: Consiglio Nazionale delle Ricerche

EDUSI: Estrategia de Desarrollo Urbano Sostenible e Integrado

GEA21: Grupo de Estudios y Alternativas 21

HUCA: Hospital Universitario Central de Asturias

ONU: $\quad$ Organización de las Naciones Unidas

PNOA: Plan Nacional de Ortofotografía Aérea

UNICEF: United Nations Internacional Children's Emergency Fund 